\title{
Lentiviral vector-based SARS-CoV-2 pseudovirus enables analysis of neutralizing activity in COVID-19 convalescent plasma
}

\section{Authors:}

Cevriye Pamukcu ${ }^{1,2}$, Elif Celik ${ }^{1,2,}{ }^{*}$, Ebru Zeynep Ergun ${ }^{1, *}$, Zeynep Sena Karahan ${ }^{1,}{ }^{*}$, Gozde Turkoz $^{1}$, Mertkaya Aras ${ }^{1,2}$, Canan Eren ${ }^{3}$, Uluhan Sili ${ }^{4,5}$, Huseyin Bilgin ${ }^{5}$, Ilke Suder ${ }^{1}$, Baris Can Mandaci $^{1}$, Baran Dingiloglu${ }^{6}$, Ozge Tatli ${ }^{6,7}$, Gizem Dinler Doganay ${ }^{6}$, Safa Baris ${ }^{4,8}$, Nesrin Ozoren ${ }^{1}$ and Tolga Sutlu ${ }^{1}$

*Authors contributed equally

\section{Affiliations:}

${ }^{1}$ Boğaziçi University, Department of Molecular Biology and Genetics, Istanbul, Turkey

${ }^{2}$ Sabancı University, Faculty of Engineering and Natural Sciences, Istanbul, Turkey

${ }^{3}$ Marmara University, Pendik Education and Research Hospital Blood Bank, Istanbul, Turkey

${ }^{4}$ Marmara University, Faculty of Medicine, Department of Pediatric Allergy-Immunology, Istanbul, Turkey

${ }^{5}$ Marmara University, Faculty of Medicine, Department of Infectious Diseases and Clinical Microbiology, Istanbul, Turkey

${ }^{6}$ Istanbul Technical University, Department of Molecular Biology and Genetics, Istanbul, Turkey

7 İstanbul Medeniyet University, Department of Molecular Biology and Genetics, Istanbul, Turkey

8 Istanbul Jeffrey Modell Diagnostic and Research Center for Primary Immunodeficiencies, Istanbul, Turkey

\section{Correspondence:}

Dr. Tolga Sutlu

Boğaziçi University, Department of Molecular Biology and Genetics Kuzey Kampus, Kuzey Park 320. 34342 Bebek / Istanbul / Turkey

Tel : $\quad+90(212) 3597158$

e-mail : tolga.sutlu@boun.edu.tr

\section{Keywords:}

SARS-CoV-2, COVID-19, Pseudovirus, Neutralizing antibody, D614G, Convalescent Plasma

\section{Financial Support:}

This project was supported by the following grants:

- Boğaziçi University Research Fund (Grant number: 17261)

- The Scientific and Technological Research Council of Turkey (TUBITAK) 1004 Program (Grant number: 18AG020) 


\section{Abstract}

As the COVID-19 pandemic caused by Severe Acute Respiratory Syndrome Coronavirus 2 (SARS-CoV-2) continues to spread around the globe, effective vaccination protocols are under deployment. Alternatively, the use of convalescent plasma (CP) therapy relies on the transfer of the immunoglobulin repertoire of a donor that has recovered from the disease as a means of passive vaccination. While the lack of an effective antiviral treatment inadvertently increases the interest in CP products, initial clinical evaluation on COVID-19 patients revealed that critical factors determining the outcome of CP therapy need to be defined clearly if clinical efficacy is to be expected. Measurement of neutralizing activity against SARS-CoV-2 using wildtype virus presents a reliable functional assay but the availability of suitable BSL3 facilities for virus culture restricts its applicability. Instead, the use of pseudovirus particles containing elements from the SARS-CoV-2 virus is widely applied to determine the activity of CP or other neutralizing agents such as monoclonal antibodies.

In this study, we present our approach to optimize GFP-encoding lentiviral particles pseudotyped with the SARS-CoV-2 Spike and Membrane proteins for use in neutralization assays. Our results show the feasibility of pseudovirus production using a C-terminal truncated Spike protein which is greatly enhanced by the incorporation of the D614G mutation. Moreover, we report that the use of Sodium Butyrate during lentiviral vector production dramatically increases pseudovirus titers. Analysis of CP neutralizing activity against particles pseudotyped with wildtype or D614G mutant Spike protein in the presence or absence the $\mathrm{M}$ protein revealed differential activity in $\mathrm{CP}$ samples that did not necessarily correlate with the amount of anti-SARS-CoV-2 antibodies.

Our results indicate that the extent of neutralizing activity in CP samples depends on the quality rather than the quantity of the humoral immune responses and varies greatly between donors. Functional screening of neutralizing activity using pseudovirus-based neutralization assays must be accepted as a critical tool for choosing CP donors if clinical efficacy is to be maximized. 


\section{Introduction}

Severe acute respiratory syndrome coronavirus 2 (SARS-CoV-2) emerged in late 2019 in China and has rapidly affected millions of people around the world leading to the COVID-19 pandemic (1-3). While the race towards an effective and long-lasting SARS-CoV-2 vaccine is in progress, there is still no effective golden standard antiviral therapy against COVID-19. Alternatively, passive immunotherapy approaches including the use of intravenous immunoglobulins (4), transfer of convalescent plasma (5) and the use of recombinant monoclonal antibodies (mAbs) as well as mAb cocktails (6-8) are currently under clinical investigation.

Convalescent Plasma (CP), used historically to treat infectious diseases (9-11), is a passive immunotherapy approach relying on the transfer of antibodies present in the serum of a person that has recently recovered from the same infection. Rich in immunoglobulins and neutralizing antibodies (nAbs), CP may help to direct complement responses against SARSCoV-2 particles as well as prevent viral entry by blocking receptor interaction, resulting in decreased viral replication (12-14). Mainly due to the lack of a better option, CP therapy has often been utilized as a potential option for treatment of COVID-19 patients $(12,15,16)$.

Concentration of nAbs in $\mathrm{CP}$ is expected correlate with the effectiveness of the treatment $(16,17)$ and it has been suggested that there is a correlation between SARS-CoV-2 specific antibody titers in CP and the severity of COVID-19 pneumonia experienced by the donor (1821). Since not all antibodies against SARS-CoV-2 antigens can be expected to have a neutralizing effect, it is critical to measure the neutralizing activity of CP for maximizing clinical benefit to the recipient. Evaluation of neutralizing activity can be carried out using the wildtype SARS-CoV-2 virus in a Biosafety Level 3 (BSL3) facility (22) or more commonly using a pseudovirus-based system in a BSL2 facility $(14,23)$

Sequencing of the SARS-CoV-2 RNA genome has revealed numerous genetic variants in the Spike protein since the onset of the pandemic. Among these, none has attracted as much attention as the D614G mutation located just outside the Receptor Binding Domain (RBD) of the Spike protein which was shown to increase SARS-CoV-2 replication and infectivity (2428). Viral entry of SARS-CoV-2 is facilitated by binding of its extensively glycosylated Spike protein to angiotensin-converting enzyme 2 (ACE2) located on the plasma membrane of host cells (29). RBD of Spike protein is shown to be crucial for this interaction and is identified to 
be a common target for neutralizing antibodies (30). Therefore, pseudovirions that express either full length $S$ protein (31) or its $\operatorname{RBD}$ are used in neutralization assays $(30,32)$. Commonly used platforms for pseudovirus generation rely on Vesicular Stomatitis Virus (VSV)-based or Human Immunodeficiency Virus 1 (HIV-1)-based vector systems (23, 33, 34). A number of studies have also included the Membrane (M), nucleocapsid ( $N$ ) and envelope (E) proteins of SARS-CoV-2 for improved virus-like particle (VLP) production $(35,36)$. In line with this, $\mathrm{Xu}$ et al. (37) reported that $\mathrm{M}$ and $\mathrm{E}$ proteins were required for efficient pseudovirus formation.

In this study, we present our efforts on developing a lentiviral vector-based pseudovirus system for SARS-CoV-2 neutralization assays. We show that the use of a D614G mutant Spike sequence and/or the use of the histone deacetylase inhibitor Sodium Butyrate significantly increased pseudovirus production while the inclusion of $M$ protein did not seem to further enhance production. Additionally, no difference was observed in the susceptibility of pseudovirus particles carrying the D614G mutation or M protein to neutralization by soluble ACE2-IgG, confirming Spike-mediated entry of pseudovirus into target 293FT cells engineered to overexpress the hACE2 gene. Analysis of CP samples using this assay revealed that a significant number of CP donations have very low neutralizing activity. This indicates that neutralization assays such as the one presented in this study should be routinely used to analyze CP activity in order to ensure clinical benefit for patients receiving therapy. 


\section{Materials and Methods}

\section{Cell lines}

The 293FT cell line was purchased from Thermo Fisher Scientific (MA, USA) and was maintained in DMEM (LONZA, Switzerland) supplemented with $10 \%$ fetal bovine serum (FBS) (HyClone, GE Healthcare, USA), 0.1 mM nonessential amino acids (HyClone), 6 mM Lglutamine (HyClone), 1 mM sodium pyruvate (HyClone), and $20 \mathrm{mM}$ HEPES (HyClone). Cells were passaged 1:4 to 1:6 depending on confluency, never allowed to reach above $90 \%$ and were used up to 20 passages. Genetically modified 293FT-hACE2 cells were selected with a final concentration of $1 \mathrm{mg} / \mathrm{ml}$ Puromycin (Sigma-Aldrich, USA).

\section{Plasmids}

The following plasmids were used for the study: pMDLg/pRRE and pRSV-Rev packaging plasmids were gifts from Didier Trono (Addgene plasmid \#12251 and \#12253). pCMV-VSV-G plasmid encoding for the vesicular stomatitis virus glycoprotein was a gift from Bob Weinberg (Addgene plasmid \#8454). LeGO-G2, LeGO-iT2 and LeGO-iT2puro plasmids were gifts from Boris Fehse (Addgene plasmids \#25917 and \#27343). pcDNA3.1+_C-(K)DYK-ACE2 (NM_021804.2, OHu20260) encoding for Homo sapiens angiotensin I converting enzyme 2 (hACE2) was a gift from Şaban Tekin (TUBITAK-MAM). pTwist EF1 Alpha-SARS-Cov-2-S2xStrep plasmid encoding for the SARS-CoV-2 Spike protein was a gift from Nevan Krogan (Addgene plasmid \#141382). pcDNA3-sACE2(WT)-Fc(IgG1) and pcDNA3-SARS-CoV-2-S-RBDsfGFP plasmids were gifts from Erik Procko (Addgene plasmids \#145163 and \#141184). pGBW-m4134096 encoding for SARS-CoV-2 M protein was a gift from Ginkgo Bioworks (Addgene plasmid \#152039).

\section{Cloning}

For the overexpression of hACE2 protein on 293FT cells, LeGo-ACE2-iT2 and LeGo-ACE2iT2puro vectors were constructed. All primers were synthesized by Sentromer DNA Technologies, TR. hACE2 region from pcDNA3.1+_C-(K)DYK-ACE2 was Polymerase Chain Reaction (PCR) amplified using forward primer containing Notl Cut site, 5'- AAT GCG GCC GCC ACC ATG TCA AG-3' and the reverse primer containing Notl Cut Site 5'- TAT GCG GCC GCT TAA AAG GAG GTC TGA A-3' (restriction sites underlined). For preparation of the vector, LeGO-iT2 and LeGO-iT2puro plasmids were cut by Notl-HF (New England Biolabs (NEB), USA) 
and ligation with the Notl digested PCR products was performed for 1 hour at room temperature with T4 DNA ligase (NEB). Colonies were screened by restriction digestion for the directional insertion of PCR products and the resulting lentiviral vectors were validated by Sanger sequencing.

Full-length SARS-CoV-2 Spike gene and the 19 aminoacid truncated version without the endoplasmic reticulum retention signal (ERRS) (Spike $\Delta 19)$ regions from pTwist-EF1-AlphaSARS-Cov-2-S-2xStrep were PCR amplified using the same forward primer containing BamHI cut site, 5'-TTA TGG ATC CGC CGC CAC CAT GTT TGT T-3' and different reverse primers containing BamHI cut sites 5'- GGC GCG GAT CCT TAC GTG TAG TGC AAT T-3' and 5'- GTG TGG GAT CCT TAG CAG CAA CTA CCG C-3'. pCMV-VSV-G was cut by BamHI-HF (NEB) for removing the VSV-G coding region and the digested PCR products were cloned into this site. Ligations were performed with T4 DNA ligase (NEB) for 15 minutes at room temperature followed by 1 hour at $16^{\circ} \mathrm{C}$. The generated vectors were named pCMV-Spike and pCMVSpike $\Delta 19$ and constructs were validated by Sanger sequencing.

The D614G variants on both pCMV-Spike and pCMV-Spike $\Delta 19$ plasmids were generated by site-directed mutagenesis. For point mutation on D614, pCMV-Spike and pCMV-Spike $\Delta 19$ plasmids were PCR amplified using a forward primer 5' - CAG TTC TTT ATC AGG GCG TGA ATT GTA CAG AG-3' and a reverse primer 5'- TCT GTA CAA TTC ACG CCC TGA TAA AGA ACT GC-3. Dpnl (NEB) restriction enzyme was used to remove unmodified plasmids and the PCR products were transformed into Top10 (Thermo Scientific, USA) E.coli for amplification. The generated vectors were named pCMV-Spike(D614G) and pCMV-Spike 1 19(D614G) and the mutagenesis was validated by Sanger sequencing.

\section{Production of recombinant soluble proteins}

For production of soluble proteins (RBD-GFP and ACE2-IgG1), 293FT cells $\left(6 \times 10^{6}\right)$ were seeded in poly-L-lysine (Sigma, USA) coated 100mm tissue culture dishes (Corning, USA). When cells reached 70\% confluency on the following day, they were transfected with the 15 $\mu \mathrm{g}$ of the plasmids (either pcDNA3-SARS-CoV-2-S-RBD-sfGFP or pcDNA3-sACE2(WT)-Fc) using calcium phosphate precipitation in the presence of $25 \mu \mathrm{M}$ chloroquine. After 8-10 $\mathrm{h}$ incubation, medium was changed with complete DMEM containing $5 \mathrm{mM}$ sodium butyrate (NaBut). The supernatants were collected at 48-60 $\mathrm{h}$ after medium change and centrifuged at $300 \mathrm{~g}$ for 5 mins to remove cell debris. After centrifugation, the supernatants were filtered 
through $0.45 \mu \mathrm{m}$ filters. Filtered supernatants of RBD-GFP were aliquoted and stored at $-20^{\circ} \mathrm{C}$ as required.

Filtered supernatant of ACE2-IgG1 was diluted 1:3 with Buffer A (20 mM Sodium Phosphate, pH 7.4, $150 \mathrm{mM} \mathrm{NaCl}$ ) and captured by HiTrap MabSelectSure (Cytiva) 1mL column using ÄKTA Avant 25 (GE Healthcare). The column was then washed with $7.5 \mathrm{CV}$ Buffer A. Captured ACE2-IgG1 was eluted with $10 \mathrm{CV}$ Buffer B (100 mM Glycine, pH 3.0) and fractionated in tubes already containing $15 \mu \mathrm{L}$ Buffer $\mathrm{C}(1 \mathrm{M}$ Tris $\mathrm{pH}$ 8.5). Collected proteins were buffer exchanged into PBS via multiple rounds of centrifugation in 10 kDA ultrafiltration tubes (Merck, USA). The purified protein content was measured by Bradford assay (B6916, Sigma-Aldrich) and analyzed under reducing conditions with 12\% SDS-PAGE, followed by wet transfer on PVDF Membrane (Merck). The membrane was blocked with 5\% skimmed milk in TBS-T and incubated overnight at $4^{\circ} \mathrm{C}$ with polyclonal rabbit anti humanACE2 antibody (\#4355), (Cell Signaling Technology (CST), USA). The dilution was prepared as 1:1000 in \%5 Bovine Serum Albumin (BSA) in TBS-T. After washing with TBS-T, membrane was treated with HRP-conjugated anti-rabbit IgG (\#7074, CST) and incubated $1 \mathrm{~h}$ at room temperature. The band was visualized using ECL (Advansta, USA) on a gel documentation system (Syngene, G BOX) for validation of the purity and size of the produced ACE2-IgG protein.

\section{Generation human ACE2 over-expressing cells}

For production the LeGo-hACE2-iT2puro vector, 293FT cells $\left(6 \times 10^{6}\right)$ were seeded in a poly-Llysine coated $100 \mathrm{~mm}$ tissue culture dish and when cells reached $\% 70$ confluency on the following day, they were transfected with the following mixture of plasmids; $7.5 \mu \mathrm{g}$ of LeGo-

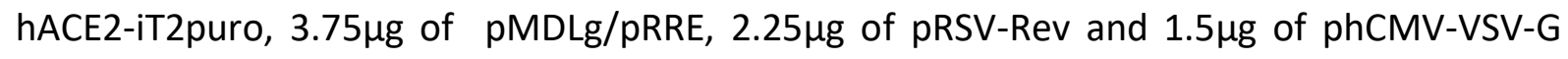
using Calcium Phosphate transfection in the presence of $25 \mu \mathrm{M}$ chloroquine. After 8-10h medium was changed and the supernatants were collected at $24 \mathrm{~h}$ after medium change, filtered with $0.45 \mu \mathrm{m}$ filters, mixed at a $1: 5(\mathrm{v} / \mathrm{v})$ ratio with $50 \%$ PEG8000 solution and stored at $4^{\circ} \mathrm{C}$ overnight. Next day, lentiviral particles were concentrated by centrifugation at $3000 \mathrm{~g}$ for 30 minutes. Supernatants were removed and pellets resuspended in $500 \mu l$ serum-free DMEM.

For generation of 293FT-hACE2 cells, $1 \times 10^{6} 293 \mathrm{FT}$ cells were seeded into a T25 flask one day prior to viral transduction. Cells were transduced with the concentrated LeGo-ACE2-iT2puro 
(MOI=1) vector in the presence of $8 \mu \mathrm{g} / \mathrm{ml}$ protamine sulfate overnight. Virus containing supernatant was completely removed the next day and cells were cultured in their regular growth media for 72 hours before tdTomato expression was assessed by flow cytometry. After puromycin selection, 293FT cells stably expressing wild type ACE2 protein were confirmed with flow cytometry.

\section{Flow Cytometry}

For surface staining of $293 \mathrm{FT}$-hACE2 cells, $2.5 \times 10^{5}$ cells were washed once with PBS and incubated at RT for 1 hour with $300 \mu$ of RBD-GFP supernatant collected as described above. The stained cells were washed with PBS and data acquisition was performed on BD Accuri C6 (Becton, Dickinson and Company, USA).

For data acquisition of neutralization assays, $25 \mu$ of Trypsin-EDTA (0.05\%) with phenol red (HyClone) was added for each well on the 96 -well plate and incubated at $37^{\circ} \mathrm{C}$ for 5 min. Cells were collected from wells by pipetting with PBS (containing 2\%FBS and 2mM EDTA) and data acquisition was performed on a BD Accuri C6 (Becton, Dickinson and Company, USA). All flow cytometry data were analyzed with FlowJo v10.1 (BD Biosciences).

\section{Microscopy}

For microscopy, $10^{5}$ 293FT-hACE2 cells were seeded in a poly-L-lysine coated coverslip placed in a 24-well plate and incubated overnight. The following day, coverslips were washed once with PBS, fixed with $250 \mu \mathrm{l}$ of $4 \%$ Paraformaldehyde (PFA) for 10 minutes at $37^{\circ} \mathrm{C}$ and were washed two more times with PBS. $250 \mu$ of filtered permeabilization buffer $(0.2 \%(w / v)$ Saponin, $2 \%(w / v)$ BSA) was added on the cover slips and incubated at RT for 1 hour. The permeabilized cells were washed once with PBS followed by incubation with 300 $\mu l$ of RBD-GFP supernatant at RT for 1 hour. Finally, coverslips were washed twice with PBS and mounted on slides for imaging. Images acquisition was performed on a Leica TCS SP5 confocal microscope (Leica Microsystems GmbH, Wetzlar, Germany). All samples were captured with 2048*2048-pixel resolution, 40X magnification, and z-stack images of $0.6 \mu \mathrm{m}$. Laser power, gain, and offset were kept constant for all images. Analysis of the captured images was made by Fiji distribution of Image J software 1.52p (38). Colocalization was documented by merging the three channels. 


\section{Pseudovirus production and titration}

For production of Spike-pseudotyped lentiviral particles, 293FT cells $\left(6 \times 10^{6}\right)$ were seeded in a poly-L-lysine coated $100 \mathrm{~mm}$ tissue culture dish and when cells reached $\% 70$ confluency on the following day, $7.5 \mu \mathrm{g}$ vector plasmid containing GFP reporter gene (LeGo-G2) was cotransfected using Calcium-Phosphate precipitation as described above along with $3.75 \mu \mathrm{g}$ of pMDLg/pRRE, $2.25 \mu \mathrm{g}$ of pRSV-Rev and indicated amounts of one of the envelope plasmids encoding the SARS-CoV-2 Spike protein (pCMV-Spike for full length wildtype Spike protein, pCMV-Spike $\Delta 19$ for wildtype Spike protein lacking 19 aminoacids in its $C$ terminal tail or pCMV-Spike $\Delta 19$ (D614G) for Spike protein carrying the D614G mutation and lacking the 19 amino acids in its $C$ terminal tail). In indicated experiments $1 \mu \mathrm{g}$ of the pGBW-m4134357 plasmid encoding for the SARS-CoV-2 M protein was included in this mixture. After 8-10h medium was changed and the supernatants containing pseudovirus particles were collected at $40-48$ hours after chaning medium and filtered through a $0.45 \mu \mathrm{m}$ syringe filter, divided into aliquots and stored at $-80^{\circ} \mathrm{C}$.

Virus titer was estimated by transducing $5 \times 10^{5} 293$ FT-hACE2 cells per well in a 24-well plate with $250 \mu \mathrm{l}$ viral supernatant for 16 hours in the presence of $8 \mu \mathrm{g} / \mathrm{ml}$ Protamine Sulfate. The transduced cells were cultured for 72 hours before GFP expression was analyzed by flow cytometry and the percentage of cells transduced was used to calculate as infectious units/per $\mathrm{ml}$ for the pseudovirus supernatant.

\section{Pseudovirus-based neutralization assay}

Sixteen hours prior to infection, $1 \times 10^{4} 293 \mathrm{FT}$-hACE2 cells were seeded in $100 \mu \mathrm{l}$ full growth media into flat bottom 96-well plates. Plasma samples were heat-inactivated in microcentrifuge tubes by heating to $56^{\circ} \mathrm{C}$ for 30 minutes, starting approximately 1 hour before infection of cells. At the end of heat inactivation, tubes were centrifuged in a tabletop microcentrifuge for 10 seconds at top speed to get rid of any precipitates and the supernatant was used. We used an initial plasma dilution of 1:20 and did 2-fold serial dilutions in serum-free DMEM up to 1:20480. For ACE2-IgG we used an initial concentration of $20 \mu \mathrm{g} / \mathrm{ml}$ and did 2-fold serial dilutions in serum-free DMEM up to $19 \mathrm{ng} / \mathrm{ml}$. The plasma and/or ACE2-IgG1 dilutions were mixed with pseudovirus supernatants in triplicates in the wells of a fresh 96 -well plate and incubated at $37^{\circ} \mathrm{C}$ for 1 hour. At the end of the incubation these mixtures were transferred to wells with seeded 293FT-hACE2 and incubated overnight 
in the presence of $8 \mu \mathrm{g} / \mathrm{ml}$ Protamine Sulfate. Next day (14-16h post transduction), medium was changed and cells were cultured for 72 hours before GFP expression was analyzed by flow cytometry.

Results of neutralization assays were plotted by normalization to samples where no plasma was used and the half-maximal inhibitory concentration (IC50) was calculated using 4parameter non-linear regression. The results of regression analysis were only deemed acceptable when the $R^{2}$ value was above 0.9 and the dilution factor corresponding to the calculated IC50 was used as Neutralizing Titer 50 (NT50) values.

\section{Donors and convalescent plasma samples}

This study was approved by The Turkish Ministry of Health's Scientific Research Platform (05.05.2020) and by Marmara University Clinical Research Ethics Committee (08.05.2020/554) and by Boğaziçi University Institutional Review Board for Research with Human Subjects (FMINAREK) (04.08.2020-2020/07). All donors applied voluntarily to the blood bank of Marmara University Pendik Education and Research Hospital for plasma donation. They were screened and fulfilled the criteria for convalescent plasma donation set forth in the Turkish Ministry of Health's Handbook on COVID-19 Immune Plasma Procurement and Use. All donors signed informed consent for the study. Demographic information, comorbidities, symptoms, signs, imaging and PCR results were retrospectively collected from electronic health records. Severity of the patients at the time of diagnosis was defined using the World Health Organization (WHO) ordinal scale for clinical improvement. The overall characteristics of donors are given in Table 1.

Plasma were collected from 16 convalescent donors from May to July 2020. Four healthy apheresis donors for thrombocyte collection provided control (non-convalescent) plasma samples. Criteria to become a convalescent plasma donor involved: COVID-19 infection confirmed with a positive PCR result, 14 days past after recovery with two negative PCR results or 28 days past after recovery, and a positive SARS-CoV-2 IgG antibody result. A total of $430 \mathrm{~mL}$ convalescent plasma was collected using apheresis method in a Haemonetics MCS+ system. Plasma were cryopreserved as $200 \mathrm{ml}$ per bag, while $30 \mathrm{ml}$ was spared for experimental analysis. 
bioRxiv preprint doi: https://doi.org/10.1101/2020.12.28.424590; this version posted December 29, 2020. The copyright holder for this preprint (which was not certified by peer review) is the author/funder. All rights reserved. No reuse allowed without permission.

Pamukcu et al.

\section{Data analysis and statistics}

Flow Cytometry data was analyzed using FlowJo v10.1 software (BD Biosciences). For the preparation of graphs and for statistical analysis, Prism v8.4.3 software (GraphPad Software) was used. Additional information regarding the applied statistical tests are provided in relevant figure legends. 


\section{Results and Discussion}

\section{Overexpression of hACE2 in 293FT cells}

293FT cells were genetically modified to overexpress the hACE2 receptor in order to make them permissive to infection by Spike-pseudotyped lentiviral vectors. For this purpose, the hACE2 gene was cloned into the LeGO-iT2puro vector that codes for a bicistronic transcript harboring an IRES sequence followed by the tdTomato fluorescent protein fused with puromycin resistance gene under the control of an SFFV promoter (Fig. 1). This facilitates the enrichment of genetically modified cells using puromycin selection while enabling the visual tracking of hACE2+ cells by red fluorescence. After genetic modification and puromycin selection, the enrichment of tdTomato expressing cells was validated by flow cytometry. Furthermore, we investigated the surface expression of hACE2 by using RBD-GFP fusion protein in flow cytometry and confocal microscopy. Flow cytometry staining with RBD-GFP confirmed that 293FT cells modified with LeGO-ACE2-iT2puro vector expressed high amounts of the hACE2 receptor on their cell surface while control cells modified with an empty LeGO-iT2puro vector showed no signs of RBD-GFP staining (Fig. 1A and 1B). This was further confirmed by microscopy analysis where the localization of RBD-GFP staining in the cell surface of modified 293FT cells ensured proper expression and membrane transport of the hACE2 receptor (Fig. 1C).

\section{Production of basic Spike-pseudotyped lentiviral vector}

For production of Spike-pseudotyped lentiviral vectors, SARS-CoV-2 Spike gene was cloned into the pCMV backbone used regularly for expression of the VSV-g envelope protein. The constructs prepared for pseudotyping included pCMV-Spike encoding for the wildtype Spike protein and pCMV-Spike $\Delta 19$ encoding for the wildtype Spike protein without the last 19 amino acids that act as an endoplasmic reticulum retention signal (ERRS). Moreover, sitedirected mutagenesis was employed on these two constructs to introduce the D614G mutation, resulting in two more plasmids: pCMV-Spike(D614G) and pCMV-Spike $\Delta 19$ (D614G) (Fig. 2). Pseudovirus production was carried out as outlined in Fig. 3A where one of the Spike-encoding plasmids was co-transfected into 293FT cells using calcium-phosphate precipitation along with the LeGO-G2 lentiviral transfer vector encoding the green fluorescent protein (GFP) as well as the packaging plasmids encoding for Rev and Gag/Pol. The supernatants containing pseudovirus particles were collected $48 \mathrm{~h}$ post-transfection and 
tested on 293FT-hACE2 cells for infectious capacity. Analysis of GFP gene delivery by the pseudovirus into 293FT-hACE2 cells was carried out 3-days post transduction by flow cytometry (Fig. 3E).

Our initial observations showed that the use of the full-length Spike gene without removal of the ERRS was ineffective for producing pseudotyped lentiviral particles possibly due to poor membrane translocation of the Spike protein. However, the use of pCMV-Spike $\Delta 19$ plasmid successfully yielded lentiviral particles that had the capacity to infect 293FT-hACE2 cells. Our results are in line with previous reports where the removal of the ERRS sequence has been a commonly used approach for Spike-pseudotyped vector generation $(33,39)$ while several other studies have also reported efficient pseudovirus generation with full-length Spike sequences $(40,41)$. Taken together, these results indicate that it might be possible to generate low-titer pseudovirus particles using the full-length Spike protein and use it for neutralization assays after concentrating supernatants but even in these cases, the deletion of ERRS has been shown to dramatically increase titers. In our hands, the use of Spike $\Delta 19$ for pseudovirus packaging was efficient enough to render any need for supernatant concentration obsolete.

In an effort to optimize the production of pseudovirus particles, different conditions during transfection and supernatant collection were also tested (Fig. 3). Initially, the amount of envelope plasmid encoding for the Spike protein within the transfection mixture was carefully titrated from $0.25 \mu \mathrm{g}$ to $4 \mu \mathrm{g}$ (Fig. 3B). While very low amounts of pCMV-Spike plasmid was not sufficient for optimal pseudovirus production, amounts higher than $1 \mu \mathrm{g}$ presented with even lower titers due to the toxic effects of Spike overexpression by 293FT cells. We show that under these conditions, the use of $0.5 \mu \mathrm{g}$ pCMV-Spike $\Delta 19$ was optimal for production of Spike-pseudotyped lentiviral vector particles.

Next, we investigated the use of Sodium Butyrate ( $\mathrm{NaBut}$ ) to increase pseudovirus titers as has been repeatedly reported for various other pseudotypes in the literature $(42,43)$. NaBut is known to increase retroviral and lentiviral vector production capacity of 293FT cells by activating CMV enhancer and HIV-1 LTR promoter function (44). Indeed, the addition of NaBut post-transfection dramatically increased the production of Spike-pseudotyped lentiviral particles (Fig. $\mathbf{3 C}$ ). While at higher doses NaBut seemed to have a toxic effect on 
the producer cells, we observed that the use of a $2 \mathrm{mM}$ concentration was tolerable and dramatically increased pseudovirus production.

The reduction of the amount of FBS used during vector production may positively affect final titers because the stability of viral particles in serum-containing medium might be lower. However, this approach is also considered to be a "double-edged sword" as such reduction in FBS amounts may also negatively affect the viability of the producer cells, thereby decreasing the final titer (45). Similarly, lowered incubation temperatures during vector production can also increase titer due to enhanced stability of viral particles (46) or decrease the titer due to negative metabolic effects on the producer cells (47). Therefore, we carried out a set of experiments in order to investigate whether the amount of FBS used in the collection medium or the incubation temperature had any effect on pseudovirus production (Fig. 3D). The use of different FBS amounts (2.5-10\%) or different incubation temperatures $\left(35^{\circ} \mathrm{C}\right.$ vs $\left.37^{\circ} \mathrm{C}\right)$ during production showed no significant effect on pseudovirus titers. Following these results, we decided to keep the standard protocol of using $10 \%$ FBS along with incubation at $37^{\circ} \mathrm{C}$ for pseudovirus production.

Finally, we aimed to optimize conditions for pseudovirus transduction by identifying whether the use spinoculation or long incubation times had a significant effect on the gene delivery efficiency to 293FT-hACE2 cells. Our results showed that centrifugation at $1000 x \mathrm{x}$ for 60 minutes during transduction yielded a significantly increased amount of GFP positive cells, especially in experiments where lower titer supernatants were used (Fig. 3F). We also observed that longer co-incubation of 293FT-hACE2 cells with the pseudovirus particles enhanced gene delivery efficiency up to the $24 \mathrm{~h}$ timepoint, after which there was no further increase in the amount of GFP+ cells (Fig. 3G). Taking into account practicality considerations and unnecessary risk of aerosol production during spinoculation, we have opted for not utilizing spinoculation any further for the development of neutralization assays but rather relied on $24 \mathrm{~h}$ co-incubation of the pseudovirus with 293FT-hACE2 cells.

\section{Production of enhanced pseudovirus}

We next attempted the integration of D614G mutation into the Spike gene sequence as well as the incorporation of SARS-CoV-2 $\mathrm{M}$ protein into the pseudovirus particles in order to identify the effects of these modifications on pseudovirus production, stability and neutralization response. For this purpose, pseudovirus particles carrying the D614G 
mutation and/or M protein were initially used to infect 293FT-hACE2 cells immediately after fresh collection of the supernatant as well as after a freeze/thaw cycle at $-80^{\circ} \mathrm{C}$ or incubation at $37^{\circ} \mathrm{C}$.

Our results clearly show that the D614G mutation significantly increases the efficiency of pseudovirus production (Fig. 4A) and this can, at least in part, be attributed to the radically increased stability of viral particles carrying the D614G mutation which was mostly evident at $37^{\circ} \mathrm{C}$ where the half-life of the pseudovirus particles were increased to 12 hours compared to the 5 hours observed with the wildtype Spike protein (Fig. 4B). These results are in line with reports showing increased stability and in vitro infectivity of the D614G mutant (48-50). We also observed that the incorporation of $\mathrm{M}$ protein into the particles does not affect the production efficiency but might be slightly decreasing the stability of the pseudovirus. This slight decrease of stability was most evident in freeze/thaw experiments within the context of Spike $\Delta 19$ as well as the stability of the particles at $37^{\circ} \mathrm{C}$ but was not significant when the more stable D614G mutant was used for pseudovirus production (Fig.

\section{A and 4B).}

\section{Neutralization of pseudovirus particles by soluble ACE2-IgG}

Having created four different types of pseudovirus particles, we next sought to determine whether these modifications made any difference in the neutralization of these particles by soluble ACE2-IgG. In order to analyze this, serial dilutions of purified ACE2-IgG were added into the media during the co-incubation of 293FT-hACE2 cells with pseudovirus particles. For each type of pseudovirus, the percentage of GFP+ cells was normalized to the samples where no ACE2-IgG was used. As expected, ACE2-IgG seemed to be specifically blocking the interaction of Spike with hACE2 on the target cell surface since no neutralization effect was observed when using VSV-g pseudotyped particles. No significant difference between the susceptibility of pseudoviral particles to neutralization by soluble ACE2-IgG was observed and the IC50 values calculated using these curves were around $4-8 \mu \mathrm{g} / \mathrm{ml}$. Comparison of the curves using extra sum-of-squares $\mathrm{F}$ test did not reveal any statistically significant difference between the different pseudotypes (Fig 4C and 4D).

Taken together, these results show that while the titer and stability of the pseudovirus can change according to the components used, they are still susceptible to neutralization by ACE2-IgG to the same extent. 
Analysis of neutralizing activity in convalescent plasma samples from COVID-19 patients

Having shown the successful neutralization of different pseudovirus particles with soluble ACE2-IgG, we next investigated the neutralizing activity of plasma samples from recovered seropositive COVID-19 patients that volunteered to become convalescent plasma donors. Pseudovirus containing supernatants were co-incubated with donor plasma at various dilutions ranging from $1 / 20$ to $1 / 20480$ at $37^{\circ} \mathrm{C}$ for 1 hour before they were applied in triplicates to 293FT-hACE2 cells in 96-well plates. Each donor's plasma was tested against the four different pseudotypes described in this study as well as the VSV-g pseudotype as a control (Fig. 5A). Plasma samples from seronegative healthy donors were used as negative controls and showed no neutralization effect on any pseudotype (Fig. 5B).

Using this approach, we analyzed the neutralizing activity of CP samples from 16 donors who had recovered from COVID-19 and were chosen in accordance with the guidelines of the Turkish Ministry of Health. We observed high neutralizing activity in a group of donors (Fig. 5C) while some donors showed little-to-no neutralization of the pseudovirus particles (Fig. 5D). Our analysis revealed that $7 / 16$ donors (44\%) were in this group with very low neutralizing activity where we were unable to calculate NT50 values due to the fact that even the lowest dilution of plasma used in the assay was unable to neutralize half of the pseudovirus used in the assay. For the remaining 9/16 donors (\%56), curve fitting was successful (with $R^{2}>0.9$ ) and NT50 values were calculated. These results indicate that the extent of neutralizing activity in convalescent plasma samples varies greatly and defining donors by simple IgG positivity might not be the best approach to predict the efficiency of convalescent plasma therapy.

It has previously been reported that the extent of neutralizing activity in convalescent plasma samples correlates with the severity of COVID-19 experienced by the donor, where hospitalized patients presented with much higher neutralizing activity in their plasma samples upon recovery from the disease (51-53). Confirming this observation, we find that none of the donors presenting with low-activity plasma had been hospitalized due to COVID19 and the extent of symptoms at diagnosis was generally higher in the group with highactivity CP (Table 1$)$. 


\section{Neutralizing activity does not necessarily correlate with antibody titers}

Besides curve-fitting and calculation of NT50 for the neutralization assays, we further carried out a semi-quantitative analysis of anti-SARS-CoV-2 antibodies in CP samples using WIZ Biotech's colloidal-gold based rapid detection kit in conjunction with the WIZ-A101 Portable Immunoanalyzer.

Despite observing a variation in the level of $\lg G$ and $\operatorname{lgM}$ concentrations in all plasma samples, the extent of this positivity did not necessarily correlate with neutralizing activity (Fig. 6A and 6B). While some plasma samples with high SARS-CoV-2 specific IgG titers showed high neutralization activity as expected, our results also revealed the presence of donors with high IgG positivity showing no detectable neutralizing activity as well as donors with relatively lower IgG positivity that perform better than expected. This lack of direct correlation suggests that the neutralizing activity of the plasma depends more on the quality of the humoral immune response rather than the quantity of it.

Our results also revealed donor-dependent differences in the neutralizing activity of plasma samples against the different virus pseudotypes (Fig. 6C). The extent of neutralizing activity against the different pseudotypes did not significantly change but a trend towards lower neutralization of the D614G mutant was observed. While these results are indicative of differential humoral response against the D614G mutant, the lack of knowledge on the genotype of the virus originally infecting the donor prevents us from further speculating on this issue. As a number of studies have already demonstrated increased susceptibility of the D614G mutant to neutralization $(27,54,55)$, our observations were regarded as a consequence of the higher titer and stability of the D614G pseudovirus. The response against pseudovirus particles carrying the $M$ protein also varied in a donor-dependent manner and did not have a significant effect on the NT50 values observed.

Taken together, these results indicate that the extent of neutralizing activity in convalescent plasma samples depends on the quality of humoral immune responses and varies greatly between donors. Functional evaluation of neutralizing activity using pseudovirus-based neutralization assays must be accepted as a critical indicator for choosing convalescent plasma donors if clinical efficacy is to be maximized. 


\section{Conclusion}

This report presents our efforts to optimize the production of lentiviral vector-based SARSCoV-2 pseudovirus particles and their use in neutralization assays to measure the activity of convalescent plasma samples. We primarily focused on using different variants of the Spike protein and optimizing transfection and supernatant collection conditions for optimal pseudovirus production. Our results clearly demonstrate that the removal of the ERRS in the tail of the SARS-CoV-2 Spike protein is crucial for efficient lentiviral-vector based pseudovirus packaging and the use of Spike(D614G) mutant significantly increases the titer and stability. We have also demonstrated that inclusion of Sodium Butyrate in the cell culture medium during supernatant collection dramatically increases pseudovirus production.

More importantly, our results indicate that a significant portion of CP donations defined by simple IgG positivity indeed contain very low neutralizing activity. While our sample size was inadequate to analyze clinical responses from the use of such plasma, the extent of neutralizing activity has already been identified as a significant factor in the clinical efficacy of CP therapy (56-58). Despite the imminent arrival of massive COVID-19 vaccination campaigns, a significant level of vaccine hesitancy is unfortunately expected throughout the world (59-61). Coupled with the lack of an efficient drug therapy for COVID-19, this means that treatment modalities such as CP administration or mAb-based therapeutics still need to be perfected and ready-in-place until SARS-CoV-2 is fully eradicated. Pseudovirus-based neutralization assays can play an important role in this process by identifying high-activity $\mathrm{CP}$ donations for maximizing clinical benefit. 


\section{Acknowledgements:}

The authors would like express their gratitude towards Prof. Mehmed Özkan, the President of Boğaziçi University, to Prof. İsmail Cinel, the Chief Physician of Marmara University Pendik Education and Research Hospital and to Prof. Şaban Tekin, the Director of TUBITAK-MAM Genetic Engineering and Biotechnology Institute for their continuing support during the pandemic. The authors would also like to thank Prof. Mayda Gürsel of Middle East Technical University, Prof. İhsan Gürsel of Bilkent University and Prof. Batu Erman of Boğaziçi University for fruitful discussions.

\section{Author contributions:}

C.P, E.C., E.Z.E and Z.S.K carried out cloning, cell culture, flow cytometry analysis, pseudovirus production and neutralization assays. G.T. and M.A. carried out pseudovirus production and data analysis. C.E. collected convalescent plasma samples. U.S., H.B. and S.B. contributed to donor recruitment. I.S. carried out western blot analysis and project management. B.C.M. carried out microscopy analysis. B.D., O.T. and G.D.D. carried out purification of recombinant ACE2-IgG. G.T., G.D.D. and N.O. contributed to study design and manuscript writing. T.S. conceptualized the study, analyzed data and wrote the manuscript. All authors reviewed the final version of the manuscript. 


\section{References}

1. Zhu N, Zhang D, Wang W, Li X, Yang B, Song J, et al. A Novel Coronavirus from Patients with Pneumonia in China, 2019. The New England journal of medicine. 2020 Feb 20;382(8):727-33.

2. Dhama K, Patel SK, Sharun K, Pathak M, Tiwari R, Yatoo MI, et al. SARS-CoV-2 jumping the species barrier: Zoonotic lessons from SARS, MERS and recent advances to combat this pandemic virus. Travel medicine and infectious disease. [Review]. 2020 Sep - Oct;37:101830.

3. Zhou $P$, Yang $X L$, Wang $X G$, Hu B, Zhang L, Zhang W, et al. A pneumonia outbreak associated with a new coronavirus of probable bat origin. Nature. 2020 Mar;579(7798):270-3.

4. Xie Y, Cao S, Dong H, Li Q, Chen E, Zhang W, et al. Effect of regular intravenous immunoglobulin therapy on prognosis of severe pneumonia in patients with COVID-19. The Journal of infection. [LetterComment]. 2020 Aug;81(2):318-56.

5. Ju B, Zhang $Q$, Ge J, Wang R, Sun J, Ge X, et al. Human neutralizing antibodies elicited by SARSCoV-2 infection. Nature. [Research Support, Non-U.S. Gov't]. 2020 Aug;584(7819):115-9.

6. Wang C, Li W, Drabek D, Okba NMA, van Haperen R, Osterhaus A, et al. A human monoclonal antibody blocking SARS-CoV-2 infection. Nature communications. [Research Support, Non-U.S. Gov't]. 2020 May 4;11(1):2251.

7. Tian X, Li C, Huang A, Xia S, Lu S, Shi Z, et al. Potent binding of 2019 novel coronavirus spike protein by a SARS coronavirus-specific human monoclonal antibody. Emerg Microbes Infect. [Letter]. 2020;9(1):382-5.

8. Cao Y, Su B, Guo X, Sun W, Deng Y, Bao L, et al. Potent Neutralizing Antibodies against SARSCoV-2 Identified by High-Throughput Single-Cell Sequencing of Convalescent Patients' B Cells. Cell. [Research Support, Non-U.S. Gov't]. 2020 Jul 9;182(1):73-84 e16.

9. McGUIRE LW, REDDEN WR. TREATMENT OF INFLUENZAL PNEUMONIA BY THE USE OF CONVALESCENT HUMAN SERUM: SECOND REPORT. Journal of the American Medical Association. 1919;72(10):709-13.

10. Cheng $\mathrm{Y}$, Wong R, Soo YOY, Wong WS, Lee CK, Ng MHL, et al. Use of convalescent plasma therapy in SARS patients in Hong Kong. European Journal of Clinical Microbiology and Infectious Diseases. 2005 2005/01/01;24(1):44-6.

11. Zhang JS, Chen JT, Liu YX, Zhang ZS, Gao H, Liu Y, et al. A serological survey on neutralizing antibody titer of SARS convalescent sera. Journal of medical virology. [Research Support, NonU.S. Gov't]. 2005 Oct;77(2):147-50.

12. Ahn JY, Sohn Y, Lee SH, Cho Y, Hyun JH, Baek YJ, et al. Use of Convalescent Plasma Therapy in Two COVID-19 Patients with Acute Respiratory Distress Syndrome in Korea. Journal of Korean medical science. [Case Reports]. 2020 Apr 13;35(14):e149.

13. Cunningham AC, Goh HP, Koh D. Treatment of COVID-19: old tricks for new challenges. Critical Care. [Editorial]. 2020 Mar 16;24(1):91.

14. Jiang S, Zhang $X$, Du L. Therapeutic antibodies and fusion inhibitors targeting the spike protein of SARS-CoV-2. Expert opinion on therapeutic targets. [Editorial]. 2020 Sep 17:1-7.

15. Yongchen Z, Shen H, Wang X, Shi X, Li Y, Yan J, et al. Different longitudinal patterns of nucleic acid and serology testing results based on disease severity of COVID-19 patients. Emerg Microbes Infect. [Letter]. 2020 Dec;9(1):833-6.

16. Duan K, Liu B, Li C, Zhang H, Yu T, Qu J, et al. Effectiveness of convalescent plasma therapy in severe COVID-19 patients. Proceedings of the National Academy of Sciences of the United States of America. [Research Support, Non-U.S. Gov't]. 2020 Apr 28;117(17):9490-6.

17. Barone P, DeSimone RA. Convalescent plasma to treat coronavirus disease 2019 (COVID-19): considerations for clinical trial design. Transfusion. [Review]. 2020 Jun;60(6):1123-7. 
18. Chen W, Zhang J, Qin X, Wang W, Xu M, Wang L-F, et al. SARS-CoV-2 neutralizing antibody levels are correlated with severity of COVID-19 pneumonia. Biomedicine \& Pharmacotherapy. 2020 2020/10/01/;130:110629.

19. Iyer AS, Jones FK, Nodoushani A, Kelly M, Becker M, Slater D, et al. Persistence and decay of human antibody responses to the receptor binding domain of SARS-CoV-2 spike protein in COVID-19 patients. Science immunology. [Research Support, N.I.H., Extramural Research Support, Non-U.S. Gov't]. 2020 Oct 8;5(52).

20. OKBA NMA, Muller MA, Li W, Wang C, GeurtsvanKessel CH, Corman VM, et al. SARS-CoV-2 specific antibody responses in COVID-19 patients. medRxiv. 2020:2020.03.18.20038059.

21. Wang $Y$, Zhang L, Sang L, Ye F, Ruan S, Zhong B, et al. Kinetics of viral load and antibody response in relation to COVID-19 severity. The Journal of clinical investigation. [Clinical Trial Multicenter Study Research Support, N.I.H., Extramural Research Support, Non-U.S. Gov't]. 2020 Oct 1;130(10):5235-44.

22. Nie J, Li Q, Wu J, Zhao C, Hao H, Liu H, et al. Quantification of SARS-CoV-2 neutralizing antibody by a pseudotyped virus-based assay. Nature protocols. [Evaluation Study Research Support, Non-U.S. Gov't]. 2020 Nov;15(11):3699-715.

23. Crawford KHD, Eguia R, Dingens AS, Loes AN, Malone KD, Wolf CR, et al. Protocol and Reagents for Pseudotyping Lentiviral Particles with SARS-CoV-2 Spike Protein for Neutralization Assays. Viruses. [Research Support, N.I.H., Intramural Research Support, Non-U.S. Gov't]. 2020 May $6 ; 12(5)$.

24. Hu J, He C-L, Gao Q-Z, Zhang G-J, Cao X-X, Long Q-X, et al. D614G mutation of SARS-CoV-2 spike protein enhances viral infectivity. bioRxiv; 2020.

25. Yurkovetskiy L, Wang X, Pascal KE, Tomkins-Tinch C, Nyalile TP, Wang Y, et al. Structural and Functional Analysis of the D614G SARS-CoV-2 Spike Protein Variant. Cell. [Research Support, N.I.H., Extramural Research Support, Non-U.S. Gov't]. 2020 Oct 29;183(3):739-51 e8.

26. Isabel S, Grana-Miraglia L, Gutierrez JM, Bundalovic-Torma C, Groves HE, Isabel MR, et al. Evolutionary and structural analyses of SARS-CoV-2 D614G spike protein mutation now documented worldwide. Sci Rep. [Research Support, Non-U.S. Gov't]. 2020 Aug 20;10(1):14031.

27. Plante JA, Liu Y, Liu J, Xia H, Johnson BA, Lokugamage KG, et al. Spike mutation D614G alters SARS-CoV-2 fitness. Nature. 2020 Oct 26.

28. Korber B, Fischer WM, Gnanakaran S, Yoon H, Theiler J, Abfalterer W, et al. Tracking Changes in SARS-CoV-2 Spike: Evidence that D614G Increases Infectivity of the COVID-19 Virus. Cell. [Research Support, Non-U.S. Gov't]. 2020 Aug 20;182(4):812-27 e19.

29. Hoffmann $M$, Kleine-Weber $H$, Schroeder $S$, Kruger $N$, Herrler $T$, Erichsen $S$, et al. SARS-CoV-2 Cell Entry Depends on ACE2 and TMPRSS2 and Is Blocked by a Clinically Proven Protease Inhibitor. Cell. [Research Support, Non-U.S. Gov't]. 2020 Apr 16;181(2):271-80 e8.

30. Tai W, He L, Zhang X, Pu J, Voronin D, Jiang $S$, et al. Characterization of the receptor-binding domain (RBD) of 2019 novel coronavirus: implication for development of RBD protein as a viral attachment inhibitor and vaccine. Cellular \& molecular immunology. [Research Support, N.I.H., Extramural Research Support, Non-U.S. Gov't]. 2020 Jun;17(6):613-20.

31. Amanat F, Stadlbauer D, Strohmeier S, Nguyen THO, Chromikova V, McMahon M, et al. A serological assay to detect SARS-CoV-2 seroconversion in humans. Nature medicine. [Observational Study Research Support, N.I.H., Extramural Research Support, Non-U.S. Gov't]. $2020 \mathrm{Jul} ; 26(7): 1033-6$.

32. Ni L, Ye F, Cheng ML, Feng Y, Deng YQ, Zhao H, et al. Detection of SARS-CoV-2-Specific Humoral and Cellular Immunity in COVID-19 Convalescent Individuals. Immunity. 2020 Jun 16;52(6):971-7 e3. 
33. Ou X, Liu Y, Lei X, Li P, Mi D, Ren L, et al. Characterization of spike glycoprotein of SARS-CoV-2 on virus entry and its immune cross-reactivity with SARS-CoV. Nature communications. [Research Support, Non-U.S. Gov't]. 2020 Mar 27;11(1):1620.

34. Pinto D, Park YJ, Beltramello M, Walls AC, Tortorici MA, Bianchi S, et al. Structural and functional analysis of a potent sarbecovirus neutralizing antibody. bioRxiv. [Preprint]. 2020 Apr 9.

35. Boson B, Legros V, Zhou B, Mathieu C, Cosset F-L, Lavillette D, et al. The SARS-CoV-2 Envelope and Membrane proteins modulate maturation and retention of the Spike protein, allowing optimal formation of VLPs in presence of Nucleoprotein. bioRxiv. 2020:2020.08.24.260901.

36. Siu YL, Teoh KT, Lo J, Chan CM, Kien F, Escriou N, et al. The M, E, and N structural proteins of the severe acute respiratory syndrome coronavirus are required for efficient assembly, trafficking, and release of virus-like particles. J Virol. [Research Support, Non-U.S. Gov't]. 2008 Nov;82(22):11318-30.

37. Xu R, Shi M, Li J, Song P, Li N. Construction of SARS-CoV-2 Virus-Like Particles by Mammalian Expression System. Frontiers in Bioengineering and Biotechnology. [Original Research]. 2020 2020-July-30;8(862).

38. Schindelin J, Arganda-Carreras I, Frise E, Kaynig V, Longair M, Pietzsch T, et al. Fiji: an opensource platform for biological-image analysis. Nat Methods. [Research Support, N.I.H., Extramural Research Support, Non-U.S. Gov't]. 2012 Jun 28;9(7):676-82.

39. Johnson $M C$, Lyddon TD, Suarez R, Salcedo B, LePique $M$, Graham $M$, et al. Optimized Pseudotyping Conditions for the SARS-COV-2 Spike Glycoprotein. J Virol. [Research Support, N.I.H., Extramural]. 2020 Oct 14;94(21).

40. Nie J, Li Q, Wu J, Zhao C, Hao H, Liu H, et al. Establishment and validation of a pseudovirus neutralization assay for SARS-CoV-2. Emerg Microbes Infect. [Validation Study]. 2020 Dec;9(1):680-6.

41. Yang R, Huang B, Ruhan A, Li W, Wang W, Deng $Y$, et al. Development and effectiveness of Pseudotyped SARS-CoV-2 system as determined by neutralizing efficiency and entry inhibition test in vitro. Biosaf Health. 2020 Aug 21.

42. Olsen JC, Sechelski J. Use of sodium butyrate to enhance production of retroviral vectors expressing CFTR cDNA. Hum Gene Ther. [Research Support, Non-U.S. Gov't Research Support, U.S. Gov't, P.H.S.]. 1995 Sep;6(9):1195-202.

43. Gasmi M, Glynn J, Jin MJ, Jolly DJ, Yee JK, Chen ST. Requirements for efficient production and transduction of human immunodeficiency virus type 1-based vectors. J Virol. 1999 Mar;73(3):1828-34.

44. Laughlin MA, Chang GY, Oakes JW, Gonzalez-Scarano F, Pomerantz RJ. Sodium butyrate stimulation of HIV-1 gene expression: a novel mechanism of induction independent of NF-kappa B. J Acquir Immune Defic Syndr Hum Retrovirol. [Research Support, Non-U.S. Gov't Research Support, U.S. Gov't, P.H.S.]. 1995 Aug 1;9(4):332-9.

45. Gelinas JF, Davies LA, Gill DR, Hyde SC. Assessment of selected media supplements to improve F/HN lentiviral vector production yields. Sci Rep. [Research Support, Non-U.S. Gov't]. 2017 Aug 31;7(1):10198.

46. Lee SG, Kim S, Robbins PD, Kim BG. Optimization of environmental factors for the production and handling of recombinant retrovirus. Appl Microbiol Biotechnol. [Research Support, Non-U.S. Gov't Research Support, U.S. Gov't, P.H.S.]. 1996 May;45(4):477-83.

47. Beer C, Meyer A, Muller K, Wirth M. The temperature stability of mouse retroviruses depends on the cholesterol levels of viral lipid shell and cellular plasma membrane. Virology. [Comparative Study Research Support, Non-U.S. Gov't]. 2003 Mar 30;308(1):137-46.

48. Daniloski Z, Guo X, Sanjana NE. The D614G mutation in SARS-CoV-2 Spike increases transduction of multiple human cell types. bioRxiv. [Preprint]. 2020 Jun 15. 
49. Zhang L, Jackson CB, Mou H, Ojha A, Rangarajan ES, Izard T, et al. The D614G mutation in the SARS-CoV-2 spike protein reduces S1 shedding and increases infectivity. bioRxiv. [Preprint]. 2020 Jun 12.

50. Yurkovetskiy L, Wang X, Pascal KE, Tomkins-Tinch C, Nyalile T, Wang Y, et al. SARS-CoV-2 Spike protein variant $\mathrm{D} 614 \mathrm{G}$ increases infectivity and retains sensitivity to antibodies that target the receptor binding domain. bioRxiv. [Preprint]. $2020 \mathrm{Jul} 4$.

51. Zhao J, Yuan Q, Wang H, Liu W, Liao X, Su Y, et al. Antibody Responses to SARS-CoV-2 in Patients With Novel Coronavirus Disease 2019. Clin Infect Dis. [Research Support, Non-U.S. Gov't]. 2020 Nov 19;71(16):2027-34.

52. Dogan M, Kozhaya L, Placek L, Gunter C, Yigit M, Hardy R, et al. Novel SARS-CoV-2 specific antibody and neutralization assays reveal wide range of humoral immune response during COVID-19. medRxiv. [Preprint]. 2020 Jul 8.

53. Robbiani DF, Gaebler C, Muecksch F, Lorenzi JCC, Wang Z, Cho A, et al. Convergent antibody responses to SARS-CoV-2 in convalescent individuals. Nature. [Research Support, N.I.H., Extramural Research Support, Non-U.S. Gov't]. 2020 Aug;584(7821):437-42.

54. Weissman D, Alameh MG, de Silva T, Collini P, Hornsby H, Brown R, et al. D614G Spike Mutation Increases SARS CoV-2 Susceptibility to Neutralization. Cell Host Microbe. 2020 Dec 1.

55. Hou YJ, Chiba S, Halfmann P, Ehre C, Kuroda M, Dinnon KH, 3rd, et al. SARS-CoV-2 D614G variant exhibits efficient replication ex vivo and transmission in vivo. Science. 2020 Dec 18;370(6523):1464-8.

56. Duan K, Liu B, Li C, Zhang H, Yu T, Qu J, et al. The feasibility of convalescent plasma therapy in severe COVID- 19 patients: a pilot study. medRxiv. 2020:2020.03.16.20036145.

57. Shen C, Wang Z, Zhao F, Yang Y, Li J, Yuan J, et al. Treatment of 5 Critically III Patients With COVID-19 With Convalescent Plasma. Jama. [Case Reports Research Support, Non-U.S. Gov't]. 2020 Apr 28;323(16):1582-9.

58. Chen L, Xiong J, Bao L, Shi Y. Convalescent plasma as a potential therapy for COVID-19. Lancet Infect Dis. [Comment]. 2020 Apr;20(4):398-400.

59. Dror AA, Eisenbach N, Taiber S, Morozov NG, Mizrachi M, Zigron A, et al. Vaccine hesitancy: the next challenge in the fight against COVID-19. Eur J Epidemiol. [Letter]. 2020 Aug;35(8):775-9.

60. A future vaccination campaign against COVID-19 at risk of vaccine hesitancy and politicisation. Lancet Infect Dis. 2020 Jul;20(7):769-70.

61. Freeman D, Loe BS, Chadwick A, Vaccari C, Waite F, Rosebrock L, et al. COVID-19 Vaccine Hesitancy in the UK: The Oxford Coronavirus Explanations, Attitudes, and Narratives Survey (OCEANS) II. Psychol Med. 2020 Dec 11:1-34. 


\section{Tables:}

Table 1: Characteristics and COVID-19 history of CP donors used in the study.

\begin{tabular}{lccc}
\hline & $\begin{array}{c}\text { All donors } \\
(\mathbf{n}=\mathbf{1 6})\end{array}$ & $\begin{array}{c}\text { High Activity } \\
(\mathbf{n}=\mathbf{9})\end{array}$ & $\begin{array}{c}\text { Low Activity } \\
(\mathbf{n}=\mathbf{7})\end{array}$ \\
\hline Median Age (Range) & $40(\mathbf{2 5 - 5 1 )}$ & $43(35-50)$ & $36(25-51)$ \\
\hline Male / Female & $15 / 1$ & $9 / 0$ & $6 / 1$ \\
\hline CT positive (\%) & 62,5 & 77,8 & 42,9 \\
\hline Hospitalized (WHO scale $\geq \mathbf{3 )}$ (\%) & 31,3 & 55,6 & 0,0 \\
\hline Mean days from PCR+ to PCR - (Range) & $18,0(2-33)$ & $14,5(2-28)$ & $22,4(12-33)$ \\
\hline Symptoms at diagnosis (\%) & & & \\
\hline Fever & 50,0 & 66,7 & 28,6 \\
\hline Cough & 68,8 & 88,9 & 42,9 \\
\hline Shortness of breath & 31,3 & 44,4 & 14,3 \\
\hline Headache & 33,3 & 37,5 & 28,6 \\
\hline Muscle pain & 57,1 & 57,1 & 57,1 \\
\hline Nausea & 7,1 & 14,3 & 0,0 \\
\hline Diarrhea & 7,1 & 14,3 & 0,0 \\
\hline Throat ache & 26,7 & 25,0 & 28,6 \\
\hline Loss of smell & 14,3 & 0,0 & 28,6 \\
\hline Word Health Organization
\end{tabular}

* World Health Organization (WHO) ordinal scale for clinical improvement available at https://www.who.int/publications/i/item/covid-19-therapeutic-trial-synopsis 
Figures and Legends:

Figure 1:
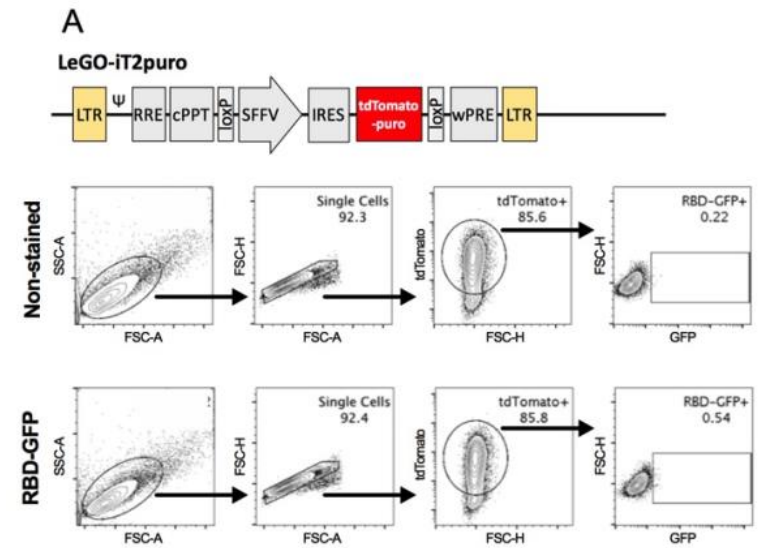

C
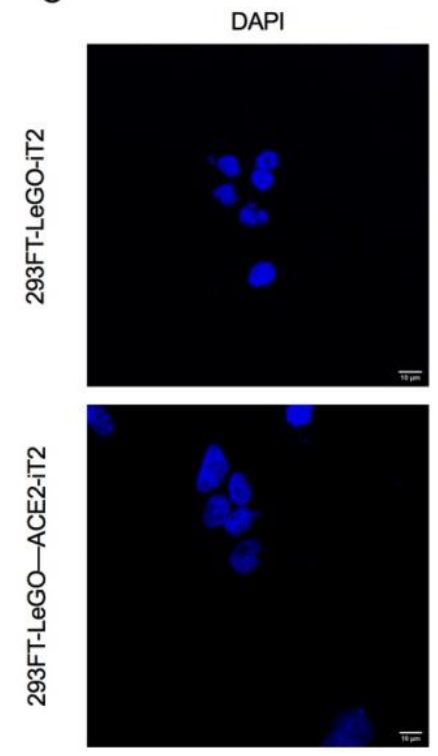

B
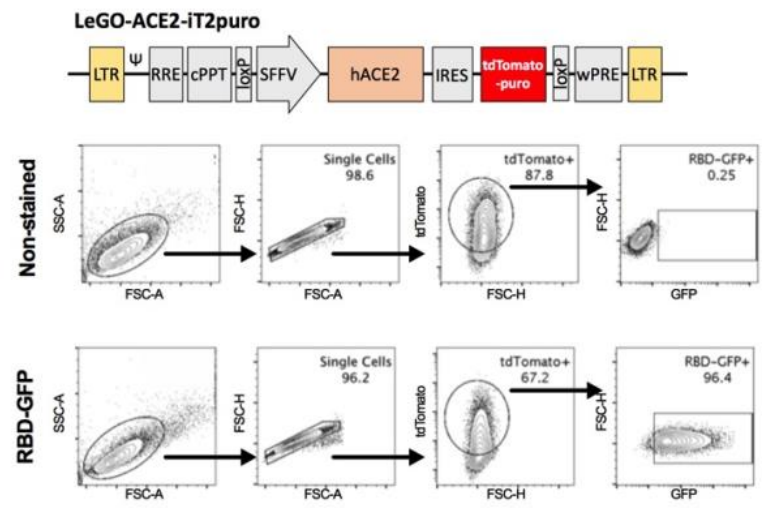

RBD-GFP
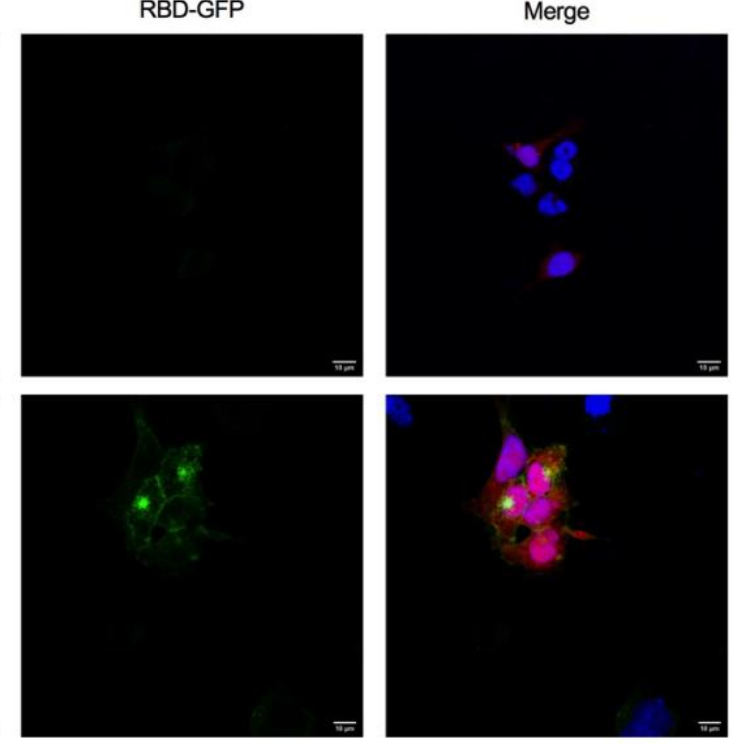

Overexpression of hACE2 in 293FT cells. Upper panels in (A) and (B) represent the maps for the empty LeGO-iT2puro vector backbone and LeGO-hACE2-iT2puro vector used to genetically modify 293FT cells. Lower panels show representative flow cytometry analysis of RBD-GFP fusion protein staining on tdTomato or hACE2-tdTomato expressing 293FT cells. (C) Representative confocal microscopy images generated from RBD-GFP fusion protein stained tdTomato and hACE2-tdTomato expressing HEK293FT cells. 
Figure 2:
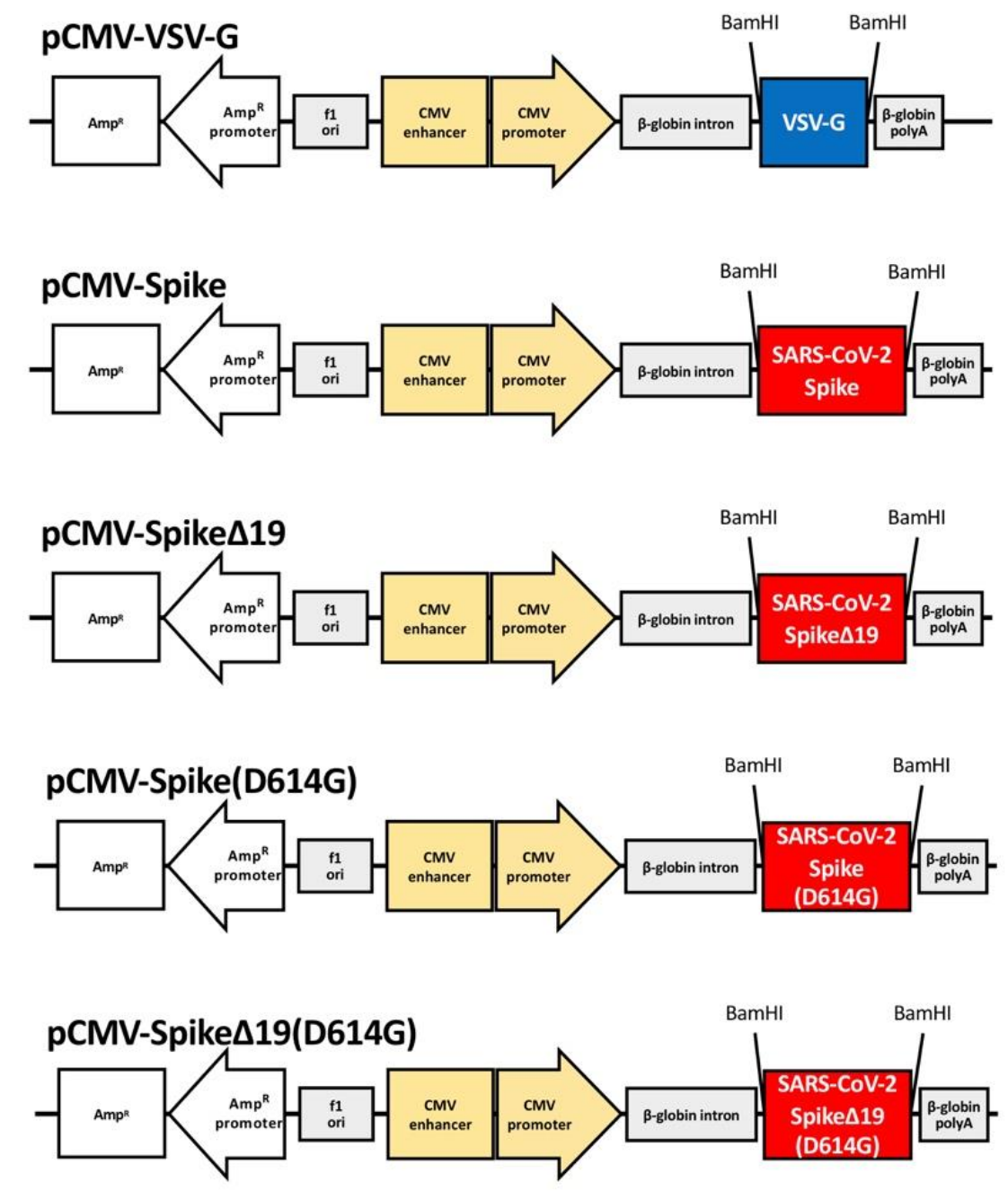

Maps of plasmids used for expression of SARS-CoV-2 Spike protein. pCMV-VSV-G backbone was used to clone different Spike sequences to be used for pseudotyping. Spike: Full length Spike protein. Spike $\Delta 19$ : Spike protein lacking 19 amino acids at the $\mathrm{C}$ terminal. Spike(D614G): D614G mutated full-length Spike. Spike 19 (D614G): D614G mutated Spike protein lacking 19 amino acids at the $C$ terminal. 
Figure 3:

A

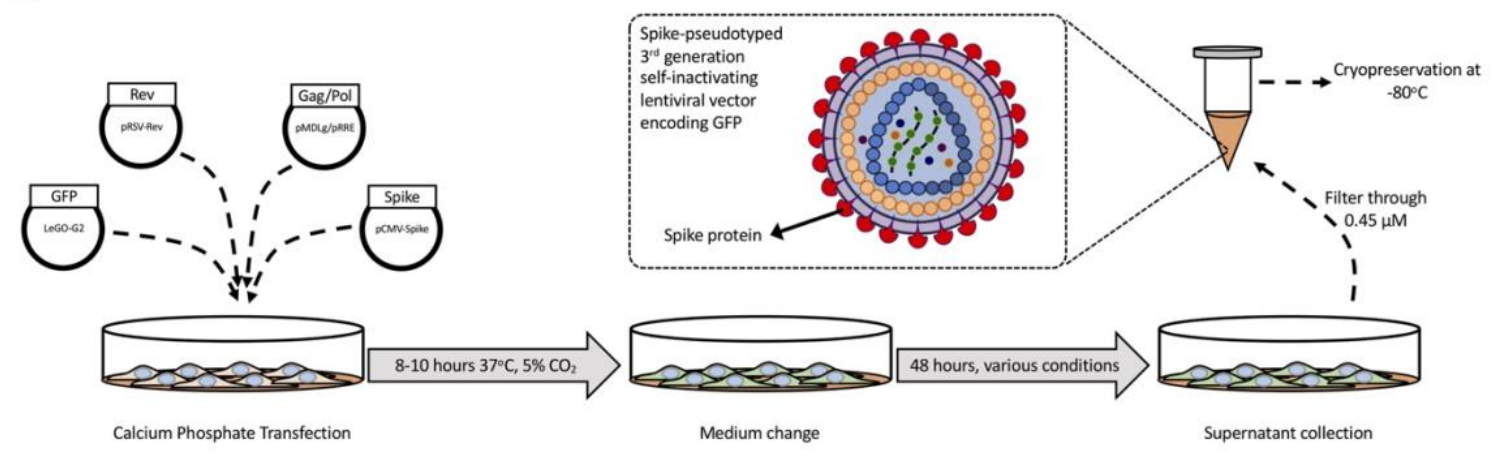

B

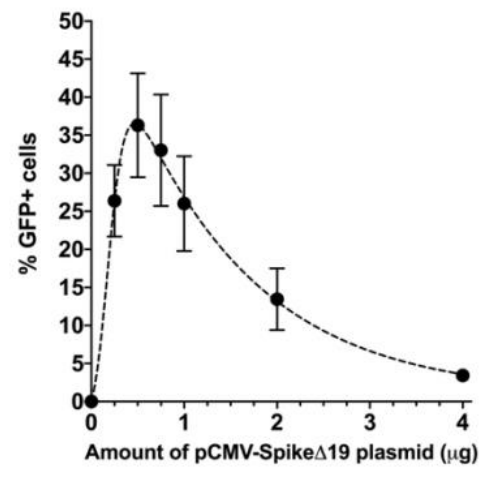

E
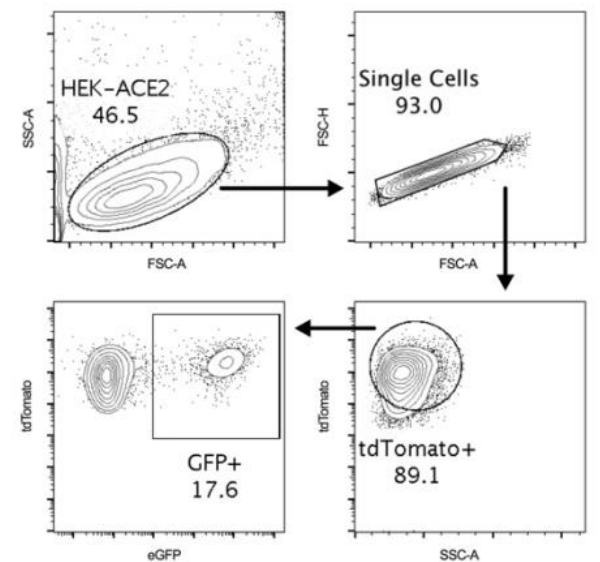

C

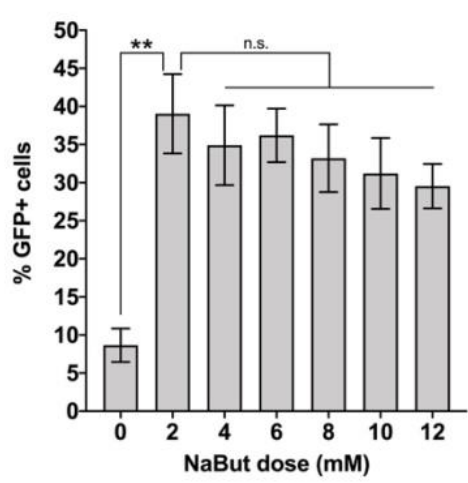

$\mathrm{F}$

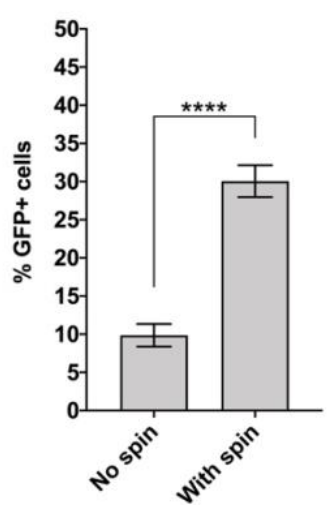

D

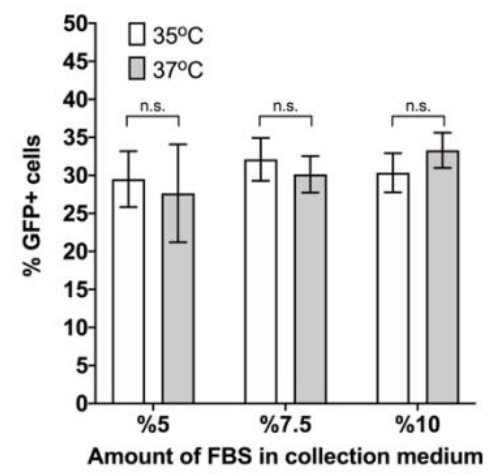

G

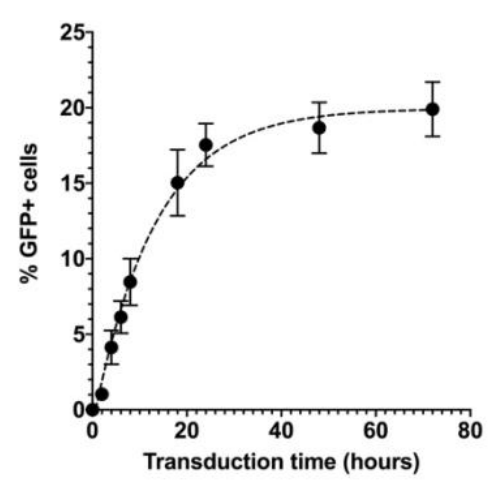

Optimization of conditions for basic pseudovirus production and transduction. (A) Representative protocol for the production of Spike-pseudotyped lentiviral vectors encoding GFP. Lego-G2 lentiviral plasmid was co-transfected into 293FT cells along with packaging constructs and the plasmid for Spike expression. Collected supernatants containing pseudovirus particles were used to infect 293FT-hACE2 cells. (B) Percentage of GFP+ 293FThACE2 cells after transduction with pseudovirus containing supernatants prepared with varying levels of the plasmid pCMV-Spike $\Delta 19$ during transfection. (Data from one representative experiment runt in triplicates, Mean +/- SEM plotted) (C) Percentage of GFP+ 293FT-hACE2 cells after transduction with pseudovirus containing supernatants collected in cull growth medium containing different concentrations of Sodium Butyrate (Data from one 
representative experiment runt in triplicates. ${ }^{* *} p<0.005$, n.s. not significant, One-way ANOVA, Tukey's test) (D) Percentage of GFP+ 293FT-hACE2 cells after transduction with pseudovirus containing supernatants collected under different concentrations of FBS and temperatures. (Data from one representative experiment runt in triplicates. n.s. not significant) (E) Representative flow cytometry analysis of GFP expression 3 days after pseudovirus treatment of 293FT-hACE2 cells. Effects of (F) spinoculation and (G) exposure time to pseudovirus during transduction of 293FT-hACE2 cells. (Data from two experiments with two different batches of pseudovirus run in triplicates, $* * * * p<0.001$, paired t-test, twotailed) 
Figure 4:

A
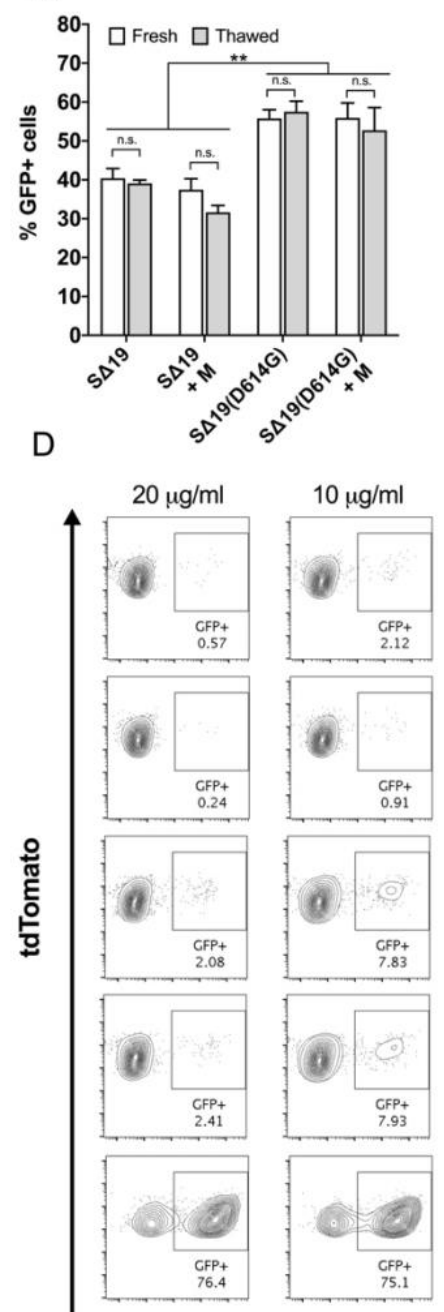

B
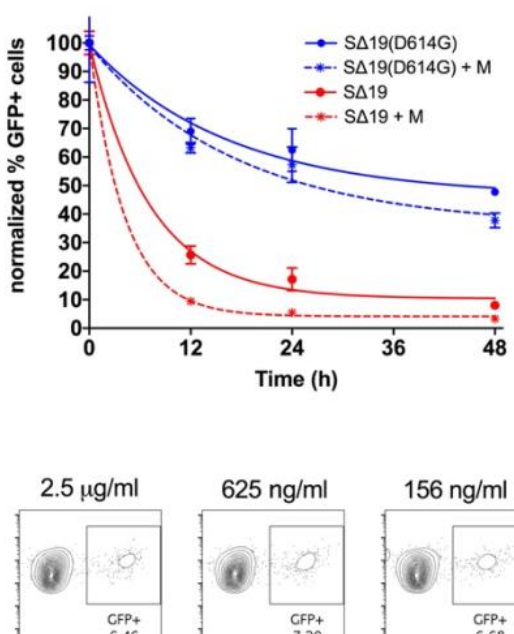

CFP+
6.46
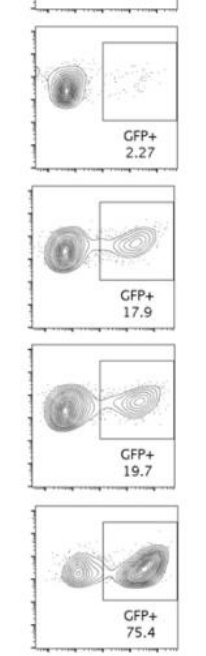
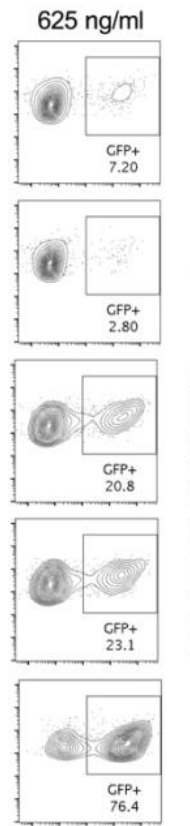

76.4
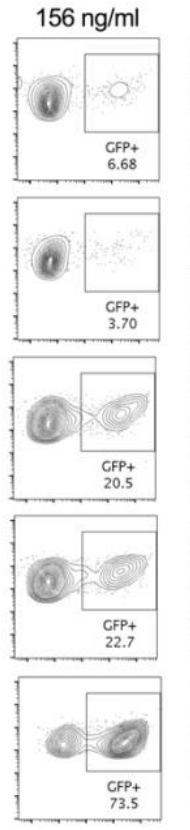

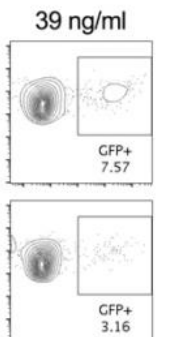

No ACE2-Ig
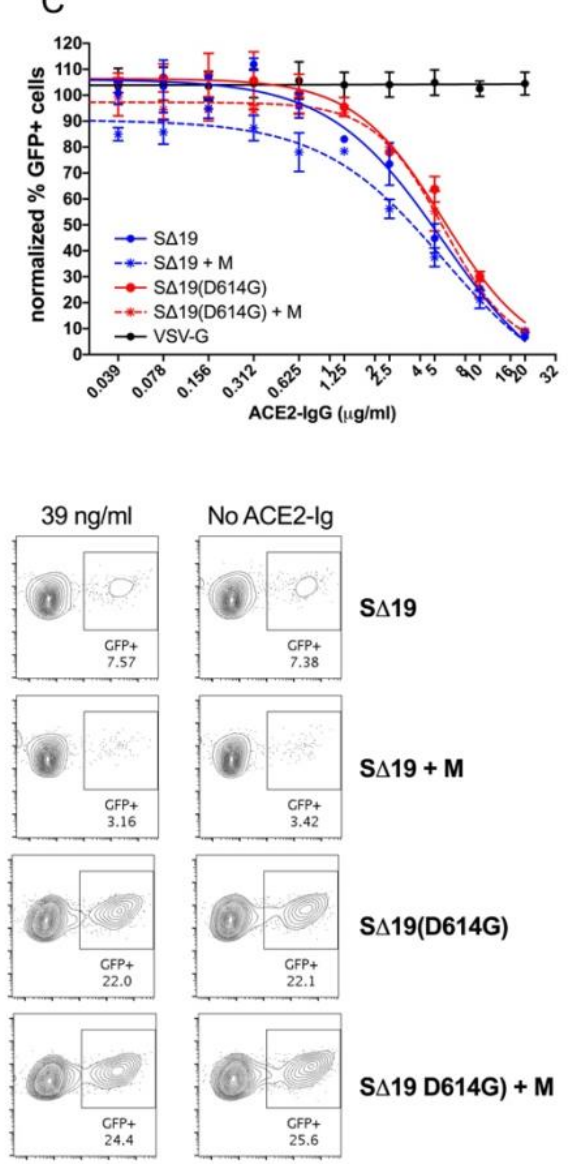

$\mathrm{S} \Delta 19 \mathrm{D614G)}+\mathrm{M}$
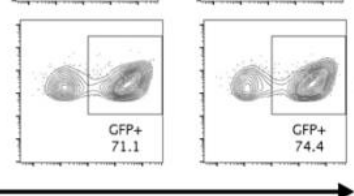

VSV-G

Development of neutralization assay using Spike-pseudoyped lentiviral vectors. (A) Percentage of GFP+ 293FT-hACE2 cells after transduction with pseudovirus containing supernatants using the WT or D614G Spike $\Delta 19$ plasmids with or without the M protein plasmid. Transductions are done with either fresh or frozen and thawed viruses. (Results from three different batches of pseudovirus each run in triplicates, ${ }^{* *} p<0.005$, two-way ANOVA, Sidak's test) (B) Stability of Spike $\Delta 19$ and Spike $\Delta 19$ (D614G) pseudoviruses with or without the $M$ protein. Pseudovirus supernatants were incubated at $37^{\circ} \mathrm{C}$ for up to 48 hours followed by transduction to tdTomato-hACE2 expressing HEK293FT cells. Data normalized to transduction results of freshly thawed supernatant. (Analyzed with one-phase decay model with least squares fit, R2>0.9 for all curves) (C) ACE2-IgG mediated neutralization of Spike $\Delta 19$ and Spike $\Delta 19$ (D614G) lentiviruses with or without M protein. Spike-pseudotype and VSV-g enveloped lentiviruses were pre-incubated with various concentrations $(20 \mu \mathrm{g} / \mathrm{ml}$ - 39ng/ml) of ACE2-IgG for 1 hour at $37^{\circ} \mathrm{C}$ followed by transduction of tdTomato-hACE2 expressing 293FT cells. VSV-G pseudotyped particles incubated with hACE2-IgG were used as control. Graph shows the percentage of GFP expressing cells as normalized to samples 
bioRxiv preprint doi: https://doi.org/10.1101/2020.12.28.424590; this version posted December 29, 2020. The copyright holder for this preprint (which was not certified by peer review) is the author/funder. All rights reserved. No reuse allowed without permission.

Pamukcu et al.

transduced without any ACE2-IgG pre-incubation. (Curve fitting was done by 4-parameter non-linear regression using variable slope, R2 values for all curves except VSV-G were above 0.9 ) (D) Results of flow based analysis of neutralization by ACE2-IgG from one representative experiment. 


\section{Figure 5:}
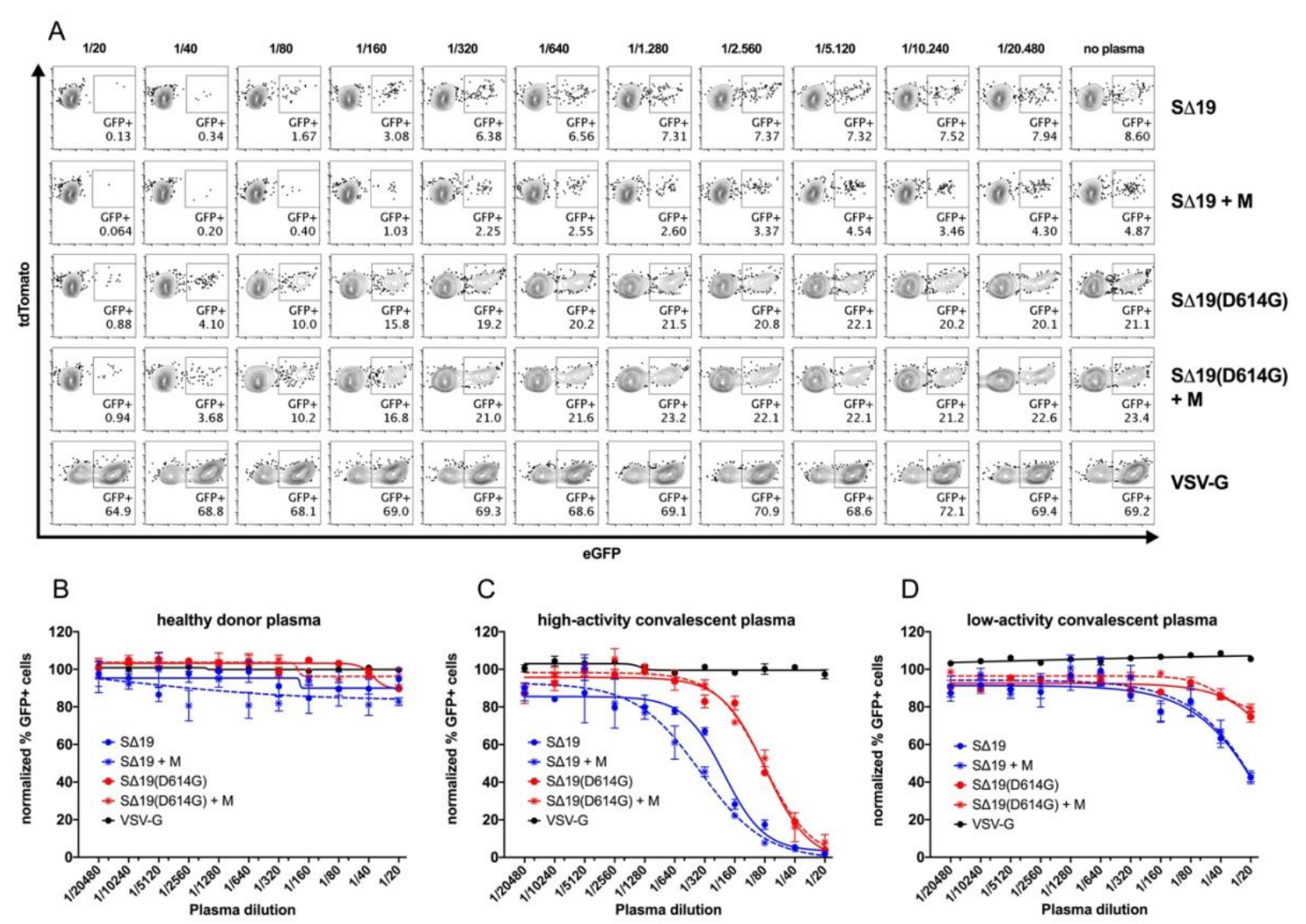

The use of Spike pseudovirus for analysis of neutralizing activity in convalescent plasma samples. Spike or VSV-G pseudotyped particles were incubated with serial dilutions (1:20 1:20480) of CP samples for 1 hour at $37^{\circ} \mathrm{C}$ followed by transduction to 293FT-hACE2 cells. VSV-G enveloped lentiviruses incubated with CP samples were used as negative controls. (A) Representative flow cytometry analysis of CP dependent neutralization assay from one donor. Plasma samples from healthy donors and 16 patients that recovered from COVID-19 were analyzed (B) Healthy donors are used as a control group and their plasma showed no neutralization effect. (Results from one representative healthy donor) (C) 9/16 of CP samples showed high neutralization activity. (Results from one representative high-activity CP) (D) 7/16 of CP samples showed no or low neutralization. (Results from one representative lowactivity (P) Curve fitting was done by 4-parameter non-linear regression using variable slope. 


\section{Figure 6:}
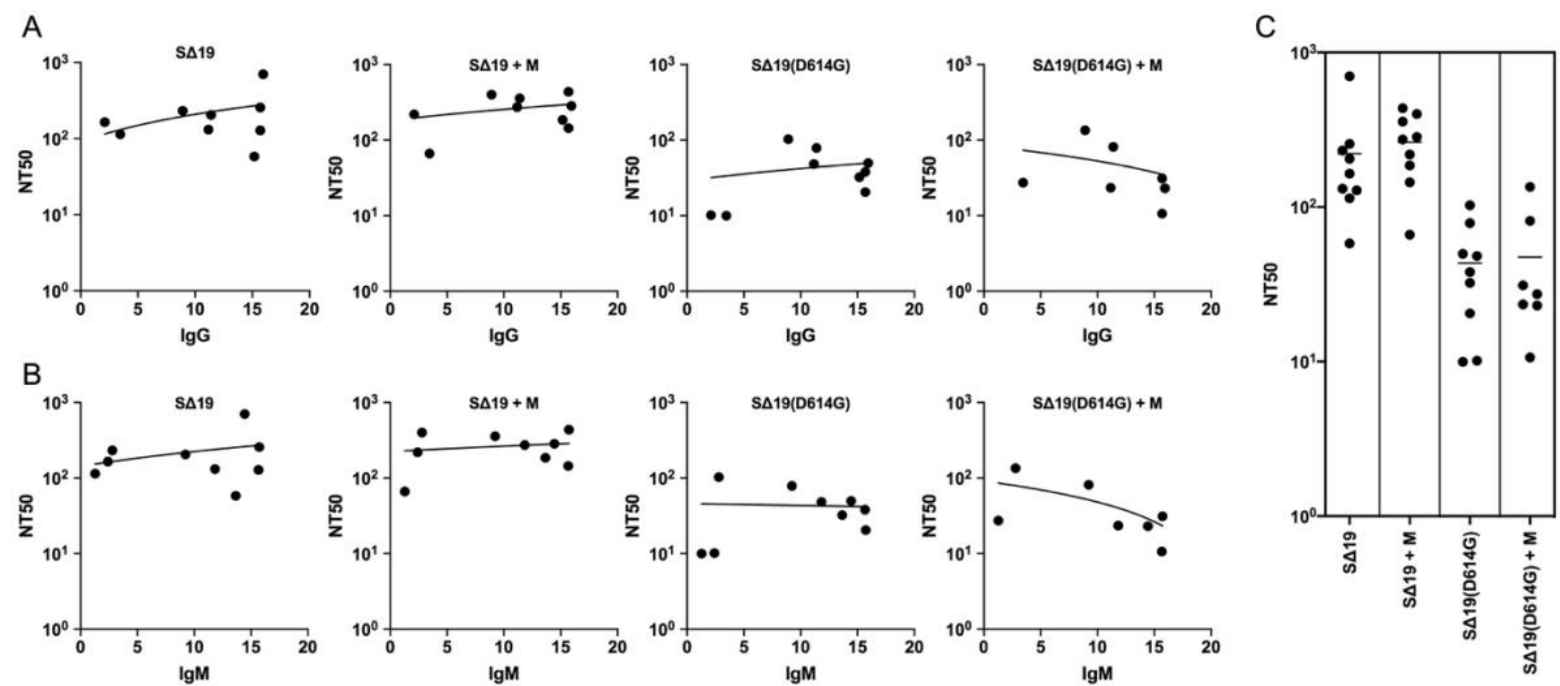

Analysis of neutralizing activity in high-activity convalescent plasma samples. The dilution factor corresponding to the calculated IC50 was used as Neutralizing Titer 50 (NT50) value. (A) NT50 values against the various pseudotypes used in this study plotted against IgG positivity measured a semi-quantitative colloidal-gold based rapid detection kit. (Lines show simple linear regression. Deviation from 0: not significant) (B) NT50 values against the various pseudotypes used in this study plotted against IgM positivity measured a semiquantitative colloidal-gold based rapid detection kit. (Lines show simple linear regression. Deviation from 0: not significant) $\quad$ (C) NT50 values of high-activity convalescent plasma samples measured against the different pseudotypes used in this study. 